EMBRYARIDDLE
Aeronautical University

SCHOLARLY COMMONS

\section{International Journal of Aviation,} Aeronautics, and Aerospace

\title{
Enhancing the Safety Training of GA Pilots to Reduce the Risk of Bird Strikes: An Experimental Pilot Study
}

Flavio A. C. Mendonca PhD

Purdue University, coimbraf@erau.edu

Thomas Carney PhD

Purdue University, tcarney@purdue.edu

Richard O. Fanjoy PhD

Purdue University, rofanjoy@purdue.edu

Follow this and additional works at: https://commons.erau.edu/ijaaa

Part of the Adult and Continuing Education Commons, Aviation and Space Education Commons, and the Aviation Safety and Security Commons

\section{Scholarly Commons Citation}

Mendonca, F. A., Carney, T., \& Fanjoy, R. O. (2018). Enhancing the Safety Training of GA Pilots to Reduce the Risk of Bird Strikes: An Experimental Pilot Study. International Journal of Aviation, Aeronautics, and Aerospace, 5(4). https://doi.org/10.15394/ijaaa.2018.1281

This Article is brought to you for free and open access by the Journals at Scholarly Commons. It has been accepted for inclusion in International Journal of Aviation, Aeronautics, and Aerospace by an authorized administrator of Scholarly Commons. For more information, please contact commons@erau.edu. 


\section{Introduction}

Birds and aviation are a dangerous combination. When aircraft and birds collide, these strikes have the potential to cause damage to aircraft and injuries to persons aboard the aircraft (MacKinnon, 2004). From 1990 through 2016 there were 179,542 wildlife strikes to aviation in the US. Ninety-seven percent of those strikes involved birds. Fifty-five percent of the strikes resulting in damage beyond repair involved birds. The risk of bird strikes and damaging bird strikes involving the general aviation (GA) community has steadily increased since 2000 both at and outside the airport environment (Dolbeer, 2018). Sixty-five percent of the aircraft destroyed due to strikes were small general aviation (GA) airplanes. During the same period, 395 persons were injured and 26 killed because of 224 and 14 bird strikes, respectively. The great majority of those injured and killed were GA pilots.

There are three approaches to mitigate the risk of a mishap due to birds: standards set by aviation stakeholders, technology, and actions by pilots. Flight crews play an important role as stakeholders in the accident prevention process (Mendonca \& Carney, 2018; Nicholson \& Reed, 2011), especially outside the airport jurisdiction where actions by airport operators have practically no effect on safety (Dolbeer, 2018; Dolbeer, Weller, Anderson, \& Begier, 2016). Previous research has addressed the safety management of wildlife strikes to aviation, especially within the airport jurisdiction (Cleary \& Dickey, 2010; DeFusco \& Unangst, 2013) but little has been done involving the GA community, especially pilots. The purpose of the current study was to investigate if a training protocol could increase Part 141 pilots' knowledge and skills to effectively mitigate the risk of aircraft accidents due to birds.

\section{Review of Literature}

A comprehensive literature review was conducted as part of this study. Major theories and concepts on aeronautical decision-making (ADM) and safety culture were analyzed to identify those which are most applicable to minimizing the threat of bird strikes by GA pilots. Further literature was examined to understand how information obtained from analyses of bird strikes can be used to enhance the safety training of aviators.

\section{Aeronautical Decision-Making}

According to the Federal Aviation Administration (FAA), aeronautical decision-making (ADM) is a systematic approach to managing risks in a unique environment - aviation (FAA, 2016a). ADM provides pilots with the knowledge and skills to identify the hazardous condition that can affect the safety of their 
flights. Most importantly, ADM concepts could be utilized to develop and implement strategies to mitigate the risks associated with those hazards (FAA, 2016b). In the past the aviation community believed that good ADM was a byproduct of flight experience. However, the investigation of high-profile accidents clearly indicates that flight experience alone will not suffice to enhance pilots' ADM processes. Moreover, previous studies suggest that effective ADM can be taught (Keller, 2015; Kochan, Jensen, Chubb, \& Hunter, 1997; O’Hare, Mullen, \& Arnold, 2010; Winter, Fanjoy, Lu, Carney, \& Greenan, 2014). The benefits of effective ADM for aviation safety has prompted the FAA to require ADM and safety risk management training be taught within Part 61 (Electronic Code of Federal Regulations, Title 14, Chapter I, Subchapter D, Part 61, 2018), and Part 141 (Electronic Code of Federal Regulations, Title 14, Chapter I, Subchapter H, Part 141, 2018) flight school ground training curricula.

The safety risk management process (SRM) is a fundamental component of ADM. Risks, such as those associated with birds, are an inherent component of the aviation industry (Ludwig, Andrews, Veen, \& Laqui, 2007). However, those risks can be mitigated through ADM processes, including SRM. The first step in the SRM process is the identification of hazards since pilots cannot mitigate risks associated with unknown hazards. Several resources could be used by pilots to identify wildlife hazards, including the Avian Hazard Advisory System (AHAS), the Airport Facility Directory (NTSB, 2009), the Aeronautical Information Publication (AIP), Notices to Airmen (NOTAMs), the Aeronautical Information Manual, and the FAA wildlife hazard website (Mendonca \& Carney, 2018). After identifying hazards, pilots should assess the risks associated with each hazard. Through the risk assessment technique, flight crews can identify the degree of risk in terms of the probability of an undesired event, and the possible consequence should it occur. If a pilot identifies risks as unacceptable, they should either suspend the activity or introduce mitigation measures to bring the risk to an acceptable level. According to the International Civil Aviation Organization (ICAO), risk mitigation strategies generally involve multiple approaches, and should address the risk severity and/or the risk probability (ICAO, 2013). Most often those strategies will have an effect on both the probability and the severity of risks.

The pillars of SRM should be the foundation of the ADM process by pilots. Most importantly, aviators should utilize SRM procedures during all stages of flight, especially pre-flight planning. Moreover, pilots must be aware that any flight operation implies risks. However, they should accept risks only when the benefits outweigh the risks (FAA, 2016a). Fliers should be provided opportunities to learn, understand, and apply effective ADM skills (FAA, 2016b). The National Transportation Safety Board (NTSB) has identified deficiencies in the flight crews' ADM processes in many major aircraft accidents (NTSB, 2003, 2009, 2013a, $2013 \mathrm{~b}, 2014)$. It is estimated that less than optimum human performance 
contributes to approximately $80 \%$ of aircraft mishaps (FAA, 2016b). On the other hand, the efficient application of ADM tenets (FAA, 2016a, 2016b) can significantly enhance safety, such as occurred with the US Airways flight 1549 in 2009 (Marra et al., 2009; NTSB, 2010). US Airways flight 1549 ditched on the Hudson river after colliding with a flock of Canada geese after departing LaGuardia airport, in New York. The flight crew experienced a total loss of thrust in both engines and had to make quick decisions during a very stressful and dangerous situation. Even though four passengers and a flight attendant were injured, the efficient pilots' ADM processes contributed to the survivability of the accident.

Multiple bird strikes after takeoff, such as occurred with US Airways flight 1549 (NTSB, 2010), will require an immediate response by the flight crew using standard operating procedures (MacKinnon, 2004). They may not have enough time to identify subsequent hazards, assess all associated risks, and develop and implement risk mitigation strategies. However, aviators generally have enough time during flight planning (and frequently during the flight) to collect information, and conduct the risk assessment process, before reaching a decision. It is important to note that an effective ADM process provides greater latitude for later options, with a significant enhancement of aviation safety. As previously noted, ADM is all about gathering information about hazards, assessing risks, developing risk mitigation strategies, and making smart and safe decisions. Therefore, ADM is applicable to the safety management of bird hazards by pilots.

\section{Safety Culture}

Safety investigators have determined that an unhealthy safety culture has been the causal factor of high-profile accidents involving safety-critical industries, such as aerospace travel, nuclear power plants, transport of hazardous materials, chemical process plants, and aviation operations. Complex systems have defenses, safeguards, and barriers, including engineered safety features (e.g., automatic controls) to protect the systems from operational hazards (Reason, 1998). However, those well-protected complex systems are extremely vulnerable to deficiencies in the safety culture of the organization.

The term "safety culture" as a contributing factor to a catastrophic event was first used during the investigation of the Chernobyl nuclear reactor complex accident in 1986 (Wiegmann, von Thaden, \& Gibbons, 2007). A poor safety culture has also been recognized as a substantive topic during the investigation of aircraft accidents (NTSB, 1992, 2013a, 2014, 2015). Several indicators help identify organizations with a sound safety culture, including organizational commitment to safety, a formal safety system, operational and work interactions (Wiegmann et al., 2007), and formal and informal safety indicators (Thaden \& Gibbons, 2008). All elements, which should have a harmonized relationship, are equally important. 
Most importantly, they should prompt the organization to unrelentingly identify safety hazards and mitigate the associated risks.

Previous research has identified the fundamental components of this multidimensional construct. The components of a safety culture include a reporting culture, a learning culture, a just culture, a flexible culture, and an informed culture (Reason 1997, 1998). It is vital to note that there are interrelationships between safety culture elements. For example, a just culture, where personnel understand the distinction between behaviors that are acceptable and those that are not, is essential for a reporting culture (Reason, 1997). According to the Civil Air Navigation Services Organization (CANSO), an informed culture, where persons have the skills and knowledge to identify hazards and associated risks in their areas of operation, relies strongly on a sound reporting culture (CANSO, 2008). According to Junior et al. (2009), personnel in a healthy safety culture apply procedures intelligently, proactively identify hazards, voluntarily report safety concerns and near misses, and have a clear understanding of the difference between errors and infractions. In addition, they feel safety is their responsibility and are empowered to mitigate risks, truly believing that safety should not come at the cost of productivity and/or profit.

Safety training and education positively affect the organization's safety culture (DeFusco, Unangst, Cooley, \& Landry, 2015). They should be a recurring activity, frequently updated, and based upon current information and safety needs (ICAO, 2013). This review ensures personnel have the knowledge and skills to competently perform their duties. Safety perceptions, values, and attitudes can be modified through education and training. Effective ADM processes by pilots (FAA, 2016a), the key elements of a sound safety culture (Reason, 1997), and the safety management of bird hazards by pilots are linked by safety training and education (Junior et al., 2009).

\section{Safety Management of Bird Hazards}

The number and rate of damaging wildlife strikes to commercial aviation have declined since 2000 (Dolbeer et al., 2016). Conversely, the number and rate of damaging strikes to GA aircraft has increased in the same period (Dolbeer, 2018). From 1990 through 2016, 97\% of the strikes and 93\% of the damaging strikes to GA aircraft occurred below 3,500 above ground level (AGL). Interestingly, during the same period more than $99 \%$ of the damaging strikes to GA happened below 10,000 feet AGL. Bird strikes that occurred between 500 feet and 3,500 feet AGL had a higher-risk of causing damage to GA aircraft, when compared to strikes below 500 feet AGL.

According to the FAA (2018), there are 19,576 landing facilities in the U.S. Of those, 5,119 are public-use, and 529 of the public-use airports are certificated 
by the FAA and served by commercial operators. Additionally, there are 14,168 private-use airports in the U.S. An overwhelming majority of those public-use and private-use airports are used solely by the GA community. Many factors contribute to the increasing risk of aircraft accidents at and around GA airports due to wildlife strikes, including constrained human and financial resources of airport operators (Cleary \& Dickey, 2010), and inadequate ADM processes by GA pilots (Mendonca \& Carney, 2018; NTSB, 2009).

The risk of aircraft accidents due to birds is intrinsic to flight operations. However, empirical data suggest that strategies by pilots following ADM processes can significantly decrease the risk, severity and/or probability of a strike (Avrenly \& Dempsey, 2014; Dolbeer, 2009, 2011; Eschenfelder \& DeFusco, 2010). For example, a Cessna Citation 1 crashed after colliding with an unknown number of American white pelicans, in March 2008, killing two pilots and three passengers. The NTSB conducted a meticulous investigation process (NTSB, 2009). The aircraft collided with birds two minutes after takeoff from Wiley Post Airport (PWA), a public use airport in Oklahoma City. The strikes occurred when the aircraft was level at approximately 1,700 feet AGL and flying at 200 knots. Because of the aircraft airspeed, the kinetic energy (KE) resulting from the strikes notably exceeded the airplane certification standards. The flight crew members had the flight experience to safely conduct this flight (NTSB, 2009). Both the bird avoidance model (BAM), an important component of the AHAS, and the FAA airport facilities directory entry for PWA contained remarks warning aviators regarding the risk of bird strikes at and around the PWA airport (NTSB, 2009). Had the pilots used the aircraft external lights (FAA, 2017; Dolbeer \& Barnes, 2017), and reduced their flight time and/or airspeed while flying through the bird-rich zone (Dolbeer, 2006; MacKinnon, 2004), the risk of this accident may have been mitigated. No single strategy will ever succeed in mitigating the risk of bird strikes, especially without the participation of pilots in the safety process (DeVault, Blackwell, \& Belant, 2013).

The safety of a flight should be a high-priority for all pilots. In case of bird hazards, the proper execution of flight-planning, and the application of ADM processes could significantly enhance aviation safety (FAA, 2016a). Previous studies have addressed the safety management of wildlife by airport operators (Cleary \& Dolbeer, 2005; Dolbeer et al., 2016; Nohara, 2016; Rillstone \& Dineen, 2013). However, little has been done to target the GA community, especially aviators. This study investigated if a safety training module could enhance the Part 141 pilots' ADM processes to mitigate the risk of bird strikes. Data were collected to answer the following research questions:

1. Is there a statistically-significant difference in pre-and posttests scores between and within the control and experimental groups? 
2. From the participants' perspective, how do 14 CFR Part 141 GA pilots manage to fly safely, given the threat of aircraft accidents due to birds?

\section{Methods}

This study used a pretest posttest experimental and control group design containing two groups (Sekaran \& Bougie, 2013). Pilots of the control group (CG) received no treatment. Pilots in the experimental group (EG) participated in a safety training workshop administered by the researchers. The safety training protocol utilized in this study was designed in an attempt to enhance Part 141 pilots' skills and knowledge pertaining to the safety risk management of birds to aviation. In addition to quantitative data, the researchers added a qualitative section to both the pretest and posttest. Moreover, a follow-up survey questionnaire was sent to participants a week after the posttest. The survey questionnaire was administered using Qualtrics ${ }^{\circledR}$ secure servers for confidentiality, privacy, and reliability considerations. Qualitative data helped the researchers to capture and better understand the participants' perspectives and perceptions regarding the safety management of birds (Patton, 2015).

For the quantitative section, the independent variable was the safety training sessions (treatment) in which each pilot who belonged to the experimental group participated. The treatment consisted of safety training developed by the researchers. The dependent variables were the pretest and posttest scores. The treatment, which is explained in a later section, was expected to significantly increase the posttest scores of the treatment group. In order to answer research question two, qualitative data were collected through three open-ended questions in both the pretest and posttest, and nine open-ended questions in a follow-up survey questionnaire. Qualitative data provided a better understanding of the quantitative findings, and helped researchers to investigate unquantifiable facts, as suggested by Patton (2015).

\section{Population and Sample}

The population for this study consisted of a subset of the GA community, flight instructors and students from an accredited Code of Federal Regulations (CFR) Part 141 flight training and four-year degree-awarding university in the Midwestern region of the United States. A mixed purposeful and probability sampling method was utilized. Initially, researchers used a convenience sampling technique to recruit pilots from the target population. Participants were then randomly distributed to the control group (CG) or to the experimental group (EG). This procedure was expected to increase the validity and credibility of the study (Patton, 2015). During the initial briefing with participants, and prior to the pretest, 
the researchers conducted a demographics assessment. Information on pilots' flight hours, flight certificates and ratings were collected (see Tables 1 and 2). Eight pilots of the experimental group (EG) completed the pretest, posttest, and follow-up survey questionnaire. Nine pilots in of the control group (CG) completed the pretest. However, only seven of the CG pilots completed the posttest, and followup survey questionnaire.

Table 1

Summary of pilots' flight hours information

\begin{tabular}{cccccc}
\hline \multicolumn{7}{c}{ Flight Hours } & & \\
\hline & N & Min. & Max. & Mean & Std. Dev. \\
Control Group (CG) & 9 & 15 & 345 & 187.78 & 115.66 \\
Experimental Group (EG) & 8 & 17 & 247 & 97.13 & 88.06 \\
\hline
\end{tabular}

Table 2

Summary of pilots' flight certificates and ratings

\begin{tabular}{|l|c|c|}
\hline $\begin{array}{l}\text { Flight Certificates and Ratings } \\
\text { (frequencies) }\end{array}$ & $\begin{array}{l}\text { Control } \\
\text { Group }\end{array}$ & $\begin{array}{l}\text { Experimental } \\
\text { Group }\end{array}$ \\
\hline $\begin{array}{l}\text { Private / Instrument / Commercial } \\
\text { Single \& Multiengine }\end{array}$ & 1 & 0 \\
\hline $\begin{array}{l}\text { Private / Instrument / Commercial } \\
\text { Single \& Multiengine / Certified Flight } \\
\text { Instructor }\end{array}$ & 1 & 2 \\
\hline Private & 2 & 2 \\
\hline Private / Instrument & 3 & 0 \\
\hline Student & 2 & 4 \\
\hline
\end{tabular}

\section{Instruments}

The safety training of pilots generally requires the use of multiple learning theories in order to be more effective (Knecht, Ball, \& Lenz, 2010). Thus, researchers incorporated several learning theories (Ertmer \& Newby, 2013) during the development and delivery of the treatment, a safety training workshop. The workshop was offered in two two-hour sessions to facilitate the participation of the Part 141 GA pilots. Empirical evidence has suggested that workshops are costeffective (Brooks-Harris \& Stock-Ward, 1999), and could assist participants to build (or enhance) new skills, attitudes, knowledge, perceptions, and competencies (Ali, Chalder, \& Madan, 2014). Both the workshop and the questions used in the pretest, posttest, and follow-up survey questionnaire were developed by the researchers after a thorough literature review covering ADM and SRM concepts (FAA, 2016a; ICAO, 2013), the safety culture tenets (CANSO, 2008, 2013; 
Reason, 1997, 1998), the safety management of wildlife by pilots (Eschenfelder \& DeFusco, 2010; MacKinnon, 2004; Mendonca, 2016; Nicholson \& Reed, 2011), the FAA Serial Report N 22 (Dolbeer et al., 2016), and one GA aircraft accident due to birds (NTSB, 2009).

The researchers devised a bank of questions consisting of 45 multiplechoice and 25 open-ended questions that could be used in the pretest, posttest, and follow-up survey questionnaire. Those questions were initially validated using the face validity process (DeVon et al., 2007) by a panel with two graduate students and two faculty members, all aviators. After the necessary modifications of the assessment instruments, researchers computed a content validity index (CVI) for each assessment tool, as suggested by Polit and Beck (2006), and Polit, Beck, and Owen (2007). A panel with six experts assisted with the CVI process. The expert panel consisted of two faculty members who are also aviators, one ICAO professional, one aviation safety professional, a senior researcher, and an experienced pilot. Initially, they were asked to rate each question in terms of their relevance to the underlying construct, the safety management of bird hazards by pilots. Then, for each question the item-CVI (I-CVI) was computed as "the number of experts giving a rating of either three or four divided by the total number of experts" (Polit \& Beck, 2006, p. 491). The items that had I-CVI below 0.78 were eliminated, as suggested by Lynn (1986). Researchers then calculated the scalelevel content validity (S-CVI), the average I-CVI across items, for both the pretest and posttest. The S-CVI for both the pretest and posttest was 0.92, and for the follow-up survey questionnaire was 0.96. An assessment instrument composed of items with I-CVI higher that 0.78 and an S-CVI higher than 0.90 is considered to have a high content validity (Polit \& Beck, 2006; Polit et al., 2007).

The pretest initially contained 25 multiple-choice questions and three openended questions. A Cronbach alpha analysis for the pretest indicated a coefficient of 0.603 , considered to be a low reliability value. Field (2009) recommends dropping items that can substantially decrease alpha. Thus, researchers dropped five multiple-choice questions from the pretest. After completing a second Cronbach alpha analysis, the overall reliability of the pretest was an acceptable 0.712 (Cortina, 1993). The pretest questions were randomly scrambled for the posttest, which had 20 questions. A Cronbach alpha for the posttest indicated a coefficient of 0.855 (high-reliability). Each question was worth 0.4 point. The follow-up survey questionnaire was composed of nine open-ended questions.

\section{Procedures}

After the Institutional Review Board (IRB) approval was obtained, participants for the study were recruited via e-mail. Invitation letters were also 
posted at the university aviation facilities (e.g., flight dispatch). The study was conducted in four phases:

1. Orientation and pretest (both groups).

2. Safety training and posttest (EG).

3. Posttest (CG).

4. Follow-up survey questionnaire (both groups).

Researchers offered two similar sessions, on different days, during phases one, two, and three so as to facilitate the participation of pilots. During the first phase researchers provided a welcome and information briefing in accordance with the IRB protocol. Participants were also asked to complete a demographics survey questionnaire, and then take the pretest. A week after phase one, researchers conducted sessions of the safety training protocol, during an interactive workshop, for the pilots in the EG. Upon termination of the safety training, participants were expected to identify aeronautical sources of bird-hazard information, integrate ADM concepts to all planning phases of their flights, and to understand safety strategies applicable to the safety management of bird hazards by pilots. It is important to note that the accident involving a Cessna Citation 500 (NTSB, 2009) was thoroughly discussed as a case study during the workshop.

Participants of the EG were asked to complete the posttest right after the safety training. The CG was solicited to take the posttest after the EG group. A week after the second session of the posttest the follow-up survey questionnaire was distributed through the Qualtrics® web-based survey software to both the EG and CG. Researchers contacted the participants through an e-mail message which included a cover letter and a link to the questionnaire. Participants had a week to answer the questionnaire. Pilots of the EG and CG answered the same questions in the same order during the pretest, posttest, and follow-up survey questionnaire. The data collection process began on September 19, 2017 and was concluded on October 15, 2017. After the data were collected and analyzed, researchers offered a similar safety training (workshop) to the participants of the CG so that all GA pilots could benefit from the study. Additionally, pilots were compensated for participating in this study.

\section{Data Analysis}

Twenty multiple-choice questions both in the pretest and posttest were quantitatively analyzed using the independent and the paired t-test. Additionally, researchers used two nonparametric statistics, the Mann-Whitney U Test, and the Wilcoxon signed-rank test since nonparametric tests are less sensitive to violations of assumptions, especially normality (Field, 2009). According to Bridge and Savilokswy (1999), nonparametric tests are generally more robust than their parametric counterparts in case of a small sample size. The researchers used the 
inductive analysis approach to analyze the qualitative data in order to discover patterns and categories. Themes were then identified and presented (Patton, 2015).

\section{Results}

Seventeen GA pilots volunteered to participate in the current study. Information concerning the participants' flight experience, certificates and ratings held was collected during the study and is shown in Tables 1 and 2. One participant, who was randomly assigned to the CG, reported a previous bird strike. This fact could have biased that participant's responses. Only the multiple-choice questions (20 in both the pretest and posttest) were quantitatively analyzed. As previously noted, eight pilots of the EG completed the entire study. However, only seven out of the nine pilots of the CG who completed pretest, concluded the posttest and follow-up survey questionnaire. Initially, researchers used the independent t-test to investigate whether there was a significant difference in scores between the pre-and posttest scores of the CG and EG. The pretest and posttest scores of the CG and the EG met the four assumptions needed to use the independent t-test (Privitera, 2015). After completing the independent t-test, researchers found that even though the EG scored higher $(M=42.00)$ than the $C G(M=38.67)$ in the pretest scores, results of the independent t-test failed to produce significant differences between groups, $\mathrm{t}(15)=-0.498, p>0.05$. However, after the workshop, the EG $(\mathrm{M}=70.00)$ scored significantly higher on the posttest than the $\mathrm{CG}(\mathrm{M}=46.29), \mathrm{t}(13)=-4.136, p<$ 0.05 , with a small effect size, $\mathrm{d}=0.19$.

There are some advantages of nonparametric procedures over parametric tests procedures. For example, they are inherently valid and robust even under very weak assumptions and/or with small sample sizes (Dwivedi, Mallawaarachchi, \& Alvarado, 2017; Wang, 2011). Considering the small sample size and possible violation of assumptions to use parametric tests, researchers completed the MannWhitney U Test, a nonparametric counterpart of the independent t-test, to determine whether there were significant differences in scores between the pre-and posttest scores of the CG and EG. All four assumptions were met for the pretest dataset (Privitera, 2015). The pretest scores of the CG (Median $=36)$ were not statistically significantly different from the EG pretest scores, $U=39, z=0.290, p>0.05$. Distributions of the posttest scores for the CG and EG were not similarly shaped, as assessed by visual inspections of the distributions of scores for both groups of the independent variable. Other three assumptions were met. The Mann-Whitney U Test showed a statistically-significant increase in the posttest scores of the participants of the EG (Mean rank =11.5) compared to their posttest scores of the CG (Mean rank =4), $U=56, z=3.270, p<0.05$, with a large effect size $(\mathrm{r}=0.84)$.

Researchers used the paired t-test to determine whether there was a significant difference in the pretest and posttest scores within each group. The 
pretest and posttest scores of the CG and the EG met the four assumptions needed to use the paired t-test (Privitera, 2015). The paired t-test for the $\mathrm{CG}$ indicated there was a small change between the pretest $(\mathrm{M}=42.29, \mathrm{SD}=12.62)$, and posttest scores, $(\mathrm{M}=46.29, \mathrm{SD}=14.58), \mathrm{t}(6)=0.716, p>0.05, \mathrm{~d}=0.28$. For the $\mathrm{EG}$, the safety training elicited a statistically-significant increase in posttest scores $(\mathrm{M}=$ $70.00, \mathrm{SD}=6.76)$ compared to the pretest scores $(\mathrm{M}=42.00, \mathrm{SD}=13.52), \mathrm{t}(7)=-$ $6.173, p<0.05$. Further analysis indicated a medium effect size $\mathrm{d}=2.18$ (Privitera, 2015). Researchers further investigated the data using the Wilcoxon signed-rank test, a nonparametric test equivalent to the paired samples t-test. The pretest and posttest scores of the CG and the EG met the three assumptions needed to use the Wilcoxon signed-rank test (Laerd Statistics, 2018). A Wilcoxon signed-rank test determined that there was a median increase in the posttest scores of the CG (Median $=52$ ) when compared to the CG pretest scores $($ Median $=36$ ), but this difference was not statistically significant, $z=0.742, p>0.05$. However, the EG did see a significant increase in the posttest scores (Median $=72$ ) when compared to the pretest scores (Median $=46), z=2.521, p<0.05$, with a large effect size, $\mathrm{r}=$ 0.89 .

Qualitative data facilitate the understanding of issues in detail and depth. As previously noted, there were three open-ended questions in both the pretest and posttest. Even though two CG participants dropped out of the study after the pretest, researchers analyzed their answers to the open-ended questions in the pretest. Their answers were expected to assist researchers in answering research question two, in addition to elucidating "what the numbers mean" (Patton, 2015, p. 15). The first open-ended question on the pretest asked participants what they would do if they found remains of a bird in the aircraft after landing, and also to explain their responses. Only two participants stated they would report the incident to the FAA. Both of them said they would report the strike to the FAA because that is mandatory for pilots. In fact, the reporting of wildlife strikes in the U.S. is encouraged, but under a voluntary reporting system (FAA, 2013). The major concern of the other participants was to inform maintenance personnel about the strike so that they could ensure the aircraft is airworthy for future flights.

ATC is required to relay advisory information on pilot-reported birdactivity at and around airports for at least 15 minutes (FAA, 2016c). The second open-ended question in the pretest asked participants why they were expected to notify air traffic control (ATC) about the presence of birds while flying. All participants demonstrated a sound understanding of this ADM consideration (FAA, 2016a) and safety culture (Reason, 1998) concept. By doing so, other pilots could utilize such information to develop SRM strategies (e.g., reduce the aircraft KE [by reducing airspeed if operationally possible]) to mitigate the risk of a bird strike (MacKinnon, 2004). 
The third open-ended question in the pretest asked participants what wildlife mitigation techniques they had been provided during their careers as pilots, and by whom. This question was an attempt to investigate if the topic wildlife (or bird) hazard management is covered during the Part 141 pilots' ground and/or flight training. Two participants did not answer this question. Responses from both groups clearly indicated that they had received little to no training on how to mitigate the risk of a bird strike. Moreover, the participants' answers indicated that the guidance they had been provided was either too generic - "if you see birds call it in and avoid collision," or inadequate - "practically no wildlife mitigation techniques as they usually fly out of the way before they become an issue."

The first open-ended question in the posttest asked what actions pilots could adopt if they were aware of the presence of birds in the takeoff path in order to mitigate the risk of a mishap. Participants of the CG, in agreement with MacKinnon (2004), focused their answers on delaying takeoff if that was possible. Similarly, the EG participants stated they would delay takeoff procedures to enhance safety. Six EG participants mentioned they would also increase the rate of climb and/or reduce the aircraft airspeed to reduce the risk of a strike (Dolbeer et al., 2016; Mendonca \& Carney, 2018; NTSB, 2009). One EG participant also mentioned pilots could reduce the engine power setting during initial climb-out, if possible, as suggested by Avrenly and Dempsey (2014). The second open-ended question inquired participants on how pilots could obtain up-to-date bird-hazard information during the cruise phase of flight. Participants of both groups provided similar responses - ATC and other pilots. One participant of the CG did not know how to answer this question. Three participants of the EG stated pilots could obtain valuable information before takeoff from the U.S. AHAS during the planning phase of their flights. The last open-ended question in the posttest asked participants about possible mitigation strategies they could take if they saw flocks of birds close to the airport. Seven and five participants of the EG and CG, respectively, stated they would notify ATC so that ATC could relay this information to other aircraft flying around the airport. Three participants of the EG also revealed they would reduce the aircraft airspeed, if operationally possible. Among them, two emphasized they would also climb to reduce the probability of a strike (Dolbeer, 2006; Dolbeer et al., 2016). Interestingly, two participants of the EG stated they would submit a wildlife-hazard report to the FAA.

The follow-up survey questionnaire was sent to participants of both groups a week after the second session of the posttest. Researchers used the Qualtrics@ web-based survey software. The survey link stayed live for seven days. The first question addressed a basic SRM concept applied to the safety management of wildlife hazards by pilots, the KE (Avrenly \& Dempsey, 2014; Mendonca \& Carney, 2018; NTSB, 2009). Participants were asked to state which factor, the aircraft airspeed or the mass of the bird, is more critical in case of a bird strike, and 
also to explain their answers. Six participants of the CG stated the aircraft airspeed is more critical than the bird mass. Among those six participants, only two mentioned the $\mathrm{KE}$ as the reason for their correct answers. Interestingly, one participant of the CG answered the bird mass because "it can do more damage to the aircraft." Participants of the EG indicated they had an adequate understanding of the KE concept applied to the safety management of birds by pilots. One EG participant added an interesting concept by arguing that the only factor in the SRM process pilots can have some control, considering those two factors, is the aircraft airspeed.

In question two, participants were asked about the safest strategy pilots could adopt to reduce the risk of a bird-strike while flying through the bird-rich zone, and also to explain their answers. Six participants of the CG suggested pilots should reduce the aircraft airspeed while flying through that hazardous area (Avrenly \& Dempsey, 2014), but none mentioned the KE concept (NTSB, 2009). Interestingly, one of those seven CG participants suggested that by reducing the aircraft airspeed pilots would give birds more time to escape from a possible strike. One CG participant stated that pilots "should avoid the bird-rich zone." Participants of the EG suggested they would reduce the aircraft airspeed and flight time while flying through the bird-rich zone if operationally possible. All participants associated the KE (Mendonca \& Carney, 2018; O'Callaghan, n.d.) and ADM concepts (FAA, 2016a), with the wildlife-strike data and information (Dolbeer, 2018) in order to reduce the probability and/or the severity of a bird-strike. Question three attempted to investigate if participants of the study would recognize the importance of reporting bird-strikes for accident prevention (Dolbeer, 2018; Reason, 1998). They were asked why they were expected to report bird-strikes, and how they could report such incidents. The GA pilots of the CG stated they would report the strike to ATC so that bird-activity information could be relayed to other traffic. One CG participant stated that pilots "should report bird strikes because they can contaminate the runway if one was to happen by the runway surface, but it can also alert other pilots to use caution for birds. Bird strikes can be reported to ATC over frequency". Conversely, responses from the EG participants suggested a better understanding of valuable safety culture and ADM concepts, the reporting of birdstrikes for safety enhancement. Seven EG participants indicated they would report the incident to the FAA using the Agency guidelines (FAA, 2013). Additionally, six of those EG participants mentioned they would report the strike to ATC so that other pilots could benefit from their report. The development and/or enhancement of safety programs by aviation stakeholders (e.g., airport operators; flight schools) tailored to mitigate the risk of wildlife strikes is highly-dependent on current wildlife-strike data (Cleary \& Dolbeer, 2005). According to Cleary \& Dickey (2010), pilots have an inherent responsibility to report hazards, including wildlife strikes and near-misses, in order to improve aviation safety. 
Empirical data indicate that the risk of damaging strikes is higher during takeoff roll and initial climb-out (Avrenly \& Dempsey, 2014; Dolbeer, 2018). The increased airspeed (MacKinnon, 2004) associated with high-power settings of engines (Avrenly \& Dempsey, 2014) could explain the highest risk of damaging strikes during those phases of flight. Question four asked participants in which phases of flight the risk of damaging strikes is the highest, and also the reason for that. The EG participants' responses indicated a sound understanding of the KE concept (NTSB, 2009) applied to the ADM process by pilots (FAA, 2016a). One EG participant stated "takeoff and climb, because the airplane is at full power (speed increases damage from a bird strike)". Participants of the CG addressed this question with different perspectives, none covering KE or ADM concepts. Quoting one CG participant "landing, the engines are operating at low rpm and would therefore be fairly quiet. As such, the birds will not have much warning from the approaching aircraft." Two CG participants correctly responded the phases of flight but provided inadequate reasons for that. One of those CG participants explained that the aircraft is less maneuverable during takeoff roll and initial climb-out, thus the risk of a damaging strike is higher. Another CG participant posited that the risk of damaging strikes is higher because pilots do not have a "great visibility in front of them, the aircraft is accelerating, and there is not much reaction time if at all."

There are several resources pilots could consult during the planning phase of their flight regarding the presence of wildlife at and around airports of interest. Some of those sources could also be used during different phases of flight. Question five was an attempt to investigate which resources participants would utilize during pre-flight planning and/or flight, or at least that they were aware, to obtain information about the presence of birds at and around airports. Participants of both groups cited important wildlife-hazard information resources (e.g., ATC; NOTAM), but only five participants of the EG mentioned the AHAS as one of those resources. Interestingly, three $\mathrm{CG}$ participants indicated pilot reports (PIREP) as a wildlife-hazard source of information. Interestingly, no participant suggested they would utilize the AIP, AIM, the FAA wildlife-hazard website, or the FAA airport facility directory as sources of wildlife hazard data and information.

Question six in the survey questionnaire, which was similar to the first openended question in the posttest, presented a scenario to investigate the participants ADM skills regarding bird hazards. They were asked which actions they would take while taxiing for takeoff if they observed birds at and near the intended takeoff runway. Five EG and one CG indicated they would delay takeoff until birds were dispersed (MacKinnon, 2004). One participant in each group stated they would use the aircraft external lights to make the aircraft more conspicuous for the birds (Doppler, Blackwell, DeVault, \& Juricic, 2015; FAA, 2017). Six CG and five EG participants indicated they would report such condition to ATC, as suggested by MacKinnon, (2004). One CG participant stated, "we could roll down the runway 
slowly and delay the liftoff until further down the runway where no birds are." One $\mathrm{CG}$ and one EG participant suggested they would request another runway for takeoff. One CG and three EG participants reported they would climb as fast as possible to reduce the probability of a strike. Quoting one EG participant "you could wait until the birds are clear of the area before you takeoff. If not possible to wait you could climb out at the aircraft's best rate of climb." No participant indicated they would reduce the aircraft airspeed (Dolbeer, 2006) and/or the engine rotation (Avrenly \& Dempsey, 2014), if operationally possible, while flying through the bird-rich zone. Moreover, no participant indicated they would submit a hazard report (Junior et al., 2015; Reason, 1997, 1998).

Question seven in the follow-up survey questionnaire asked participants which aspect of the safety management of wildlife (or birds) they were familiar with. Responses from both the CG and EG participants indicated they did not have the knowledge and skills to effectively mitigate the risk of bird strikes. Quoting one CG participant, "I am not very familiar at all." A CG participant stated "mowing the grass at airports. Noise producing guns. Targeted and controlled use of trained raptor birds patrolling the airport area". One EG participant had learned through the training protocol some strategies to mitigate the risk of bird strikes, and that prior to that knew nothing about it. Quoting another EG participant, "before almost nothing, now quite a bit more."

Effective communication and training are foundational pillars of a sustainable safety culture (CANSO, 2013), and indispensable components of the safety management of hazards (FAA, 2016a). Certificated 14 CFR Part 141 flight schools must meet rigorous standards and teach an approved curriculum in order to ensure a high-level of safety (FAA, 2016a). The courses approved by the Agency must include ground training on aeronautical knowledge areas, such as preflight planning, applicable topics in the AIM, and the safe and efficient operation of an aircraft (Electronic Code of Federal Regulations, Title 14, Chapter I, Subchapter H, Part 141, 2018). The FAA has required ADM to be taught within Part 141 collegiate flight school pilot ground training curricula. Flight training should also include preflight planning and preparation. According to the FAA (2016b), flight instructors have an inherent responsibility to train new pilots in all ADM areas, including SRM and airmanship skills, so that they can efficiently and safely operate as a certificated pilot in the National Airspace System. Thus, the topic wildlifehazard management should be covered during ground and flight training of Part 141 GA pilots.

Question eight, similar to the third open-ended question in the pretest, was an attempt to assess how (if) the safety management of wildlife hazards was addressed during ground and flight training at the targeted Part 141 flight school. Participants were asked on how the safety management of wildlife hazards was covered during flight activities. Responses from both groups were generally 
similar, and clearly indicated that this topic was barely covered during ground and flight training. Some of the participants' answers are as follow:

"Not that much"

"It definitely wasn't"

"Wildlife safety management is not really emphasized during flight training." "There are other safety management areas that are more heavily emphasized, such as SRM, ADM, and SOPs. Wildlife safety management is not well understood and so it isn't taught unless it is encountered directly"; and

"There is little discussion about bird strikes. The main thing that is gone over what to do if there is a strike. Very little is spent on educating how to find information on wildlife strikes and what to do to avoid and mitigate the risk associated with wildlife strikes."

The last question in the follow-up survey questionnaire asked participants if they had recommendations for pilots to mitigate the risk of bird strikes. The CG participants provided generic responses that could do little to nothing to reduce the risk of a mishap resulting from a bird-strike. Quoting one CG participant, "since I am not familiar enough, I do not have any recommendations except for always reporting a bird strike or advising ATC of birds that could be hazardous to flight." Conversely, the EG participants' provided recommendations based on empirical data. Three EG participants suggested pilots should use the AHAS, NOTAMs, and other sources of wildlife hazard information during the planning-phase of their flights. Four EG participants recommended, in agreement with Dolbeer (2006), that pilots could reduce the aircraft airspeed and/or reduce the flight time through the bird-rich zone. Quoting one EG participant, "just remember to be aware of the possibility of birds in the area if they are mentioned by tower or a NOTAM, especially during climb-out. If you are coming up on a bird/flock pitch up and try to climb over them because birds will generally dive to avoid us. Make sure that if a strike is inevitable or you are unsure if it will occur, pull some power back and try to reduce your airspeed so that the severity of the strike is lower". One EG participant argued that pilots should be cautious of when they are to fly through the bird-rich zone, and that they should reduce the aircraft airspeed and power setting whenever possible while remaining at a safe airspeed to prevent a stall.

\section{Discussion}

The safety training of pilots is a sound safety culture catalyst (DeFusco et al., 2015), Most importantly, training should be based on current data and safety needs, and be frequently reviewed and updated (ICAO, 2013). Flight crews should not be expected to be sufficiently informed and have the knowledge and skills to mitigate the inherent hazards of their jobs if they have not received adequate training (Manuele, 2013). Research question one asked if there would be any 
differences in pre-and post-test scores between and within the two conditions: the control and experimental groups. Eight Part 141 GA pilots participated in the safety training that was delivered as an interactive workshop. Results, using parametric and nonparametric tests, indicated that there was not a statistically significant difference between the groups on the pretest. Moreover, the CG did not appear to experience a significant change between the pretest and posttest scores. However, statistically significant results were found between the pretest and posttest scores of the EG as well as the posttest scores of the CG and EG. These findings suggest that the safety training did enhance the overall knowledge and skills of participants within the EG pertaining to the safety management of birds.

Qualitative data not only helped answer research question two, but also provided different perspectives and offered a greater depth of understanding of the quantitative data (Patton, 2015). These data were analyzed using an inductive analysis approach (Patton, 2015). Three major themes emerged from the participants responses to the open-ended questions in the pretest and posttest, and especially the follow-up survey questionnaire. The first theme that became apparent to the researchers was the participants poor familiarity with the ADM processes applicable to the safety management of birds by pilots. A key ADM pillar is SRM. The first step of the SRM process is the identification of hazards. Even though participants indicated they were capable of demonstrating how to obtain birdhazard information, most of them were not aware of important aeronautical resources that could (should) be used by pilots to mitigate the risk of strikes, such as the AHAS, airport facility directory (NTSB, 2009), the FAA wildlife hazard website, and AIM (Mendonca \& Carney, 2018). Actions by pilots can reduce the probability and/or the severity of bird strikes (Avrenly \& Dempsey, 2014; NTSB, 2009). By integrating the KE concept with wildlife strike data and information, pilots could reduce the flight time, aircraft airspeed (Dolbeer, 2006), and/or engine rotation through the bird-rich zone (Avrenly \& Dempsey, 2014) to enhance safety. Answers of the EG indicated they would incorporate those concepts after the safety training when presented a bird-strike risk condition.

A healthy safety culture is among the best defenses against the hazards that may contribute to mishaps (CANSO, 2013), such as birds. The second theme that became apparent to researchers was a misperception of the safety culture key elements, as suggested by their responses to the open-ended questions. For example, only two participants indicated in the pretest they would report a birdstrike to the FAA. Misjudgments of risks may cause ineffective ADM processes and risk behaviors with regard to aviation safety (FAA, 2016a). When challenged with situations where the risk of a bird strike was high, most responses of the CG participants were either incomplete or inadequate. Conversely, the EG participants' responses indicated, after the safety training, they had a better understanding of the inherent hazards (birds) of their working environment (Junior et al., 2009), were 
more capable of incorporating bird-hazard data into their flight planning (FAA, 2016a), and were more likely to report strikes to the FAA (Dolbeer et al., 2016).

The safety management of bird strikes, and a robust safety culture are linked by safety training (DeFusco et al., 2015). As previously noted, the topic wildlifehazard management is expected to be covered during ground and flight training of Part 141 GA pilots. The last theme, that could illuminate the previous two identified themes as well as the quantitative data (Patton, 2015), was that the topic "safety management of birds" is barely covered during ground and flight training. Participants of both groups explicitly indicated, through their answers to one and two open-ended questions in the pretest and the follow-up survey questionnaire, respectively, that flight instructors generally provide insufficient or even no guidance on how to mitigate bird-strike risks. Thus, superior safety results cannot be achieved (ICAO, 2013), nor Part 141 GA pilots could be expected to incorporate ADM concepts in all phases of flight, including pre-flight planning.

\section{Conclusions and Limitations}

The purpose of the current study was to investigate if a training protocol could increase Part 141 GA pilots' knowledge and skills to efficiently mitigate the risk of mishaps due to bird strikes. Findings indicated that a safety training protocol significantly increased the posttest scores of the EG, with a large effect size. A finding of concern was that the topic "safety management of bird hazards" has not been adequately addressed during the ground and flight training of Part 141 GA pilots. Participants of the study noticeably indicated that they had received little-tono information on this safety scheme, despite the FAA precepts requiring ADM and SRM be taught within Part 141 flight schools pilot ground training curricula. Further studies are recommended to investigate the causes of this discrepancy.

A limitation of this research project was the small sample size, which restricts the generalizability of the findings. Researchers used parametric and nonparametric statistical tests, as well as triangulation (e.g., different theories and concepts during data analysis) to analyze the data in order to increase the validity and credibility of this study (Patton, 2015; Sekaran \& Bougie, 2013). Another limitation was the small amount of flight hours by participants. The researchers acknowledge that this condition could have had an impact on findings. However, previous studies (Cleary \& Dickey, 2010; MacKinnon, 2004) indicated that GA pilots may not have the knowledge and skills to mitigate the risk of mishaps due to birds. Moreover, the investigation of accidents due to birds involving experienced pilots suggest that they may not have had the competence to mitigate the risks associated with birds during flight activities (NTSB, 2009. 2018a, 2018b). Nevertheless, further studies with a lager sample including more experienced GA pilots are recommended to further validate the current project. 


\section{Practical Applications}

Historical analyses of wildlife strike data have indicated that wildlife hazard safety programs by airport operators have reduced the number of aircraft incidents at the airport jurisdiction. However, these analyses also suggest that further actions are paramount to mitigate the risk of accidents outside the airport environment. Findings of this project shed light in previous studies by Dolbeer (2006), MacKinnon (2004), Nicholson and Reed (2011), and NTSB (2009), and suggest that actions by pilots could prevent mishaps due to birds. The topic "safety management of birds (wildlife) should be incorporated into the ground and flight training of Part 141 GA pilots. During flight training pilots could discuss pilots' strategies to mitigate the risk of strikes. Those discussions could, for example, cover sources of wildlife hazards information that should be consulted during flight planning, and pilots' actions to be taken to reduce the risk of accidents when flying through the bird-rich zone. The increasing risk of GA aircraft mishaps due to wildlife strikes (Dolbeer, 2018), and the forecast growth for the GA industry (General Aviation Manufacturers Association, 2018) require new approaches so as to continuously improve aviation safety. Providing GA pilots with the knowledge and skills to mitigate bird strikes is no longer an option, it is a requirement. 


\section{References}

Ali, S., Chalder, T., \& Madan, I. (2014). Evaluating interactive fatigue management workshops for occupational health professionals in the United Kingdom. Safety and Health at Work, 5(4), 191-197.

Avrenli, K. A., \& Dempsey, B. J. (2014). Statistical analysis of aircraft-bird strikes resulting in engine failure. Journal of the Transportation Research Board, 2449, 14-23.

Bridge, P. D., \& Sawilosky, S. S. (1999). Increasing physicians' awareness of the impact of statistics on research outcomes: Comparative power of the t-test and Wilcoxon rank-sum test in small samples applied research. Journal of Clinical Epidemiol, 52(3), 49, 229-235.

Brooks-Harris, J. E., \& Stock-Ward, S. R. (1999). Workshops: Designing and facilitating experiential learning. Thousand Oaks, CA: SAGE.

Civil Air Navigation Services Organization (CANSO). (2008). Safety culture definition and enhancement process. Retrieved from https://www.canso.org/sites/default/files/

Safety\%20Culture\%20Definition\%20and\%20Enhancement\%20Process.pdf

Civil Air Navigation Services Organization (CANSO). (2013). Safety culture and the future enhancement of ICAO provisions related to SMS implementation. Working paper presented during the 38th ICAO Assembly, Montreal, Canada. Working paper retrieved from http://www.icao.int/Meetings/a38/Documents/WP/wp206_rev1_en.pdf

Cleary, E. C., \& Dickey, A. (2010). Guidebook for addressing aircraft/wildlife hazards at general aviation airports (ACRP Report No. 32). Retrieved from the Transportation Research Board on the National Academies website: http://www.trb.org/Publications /Blurbs/163690.aspx

Cleary, E. C., \& Dolbeer, R. A. (2005). Wildlife hazard management at airports: A manual for airport personnel. Retrieved from http://www.faa.gov/airports/airport_safety/wildlife/ resources/media/2005_faa_manual_complete.pdf

Cortina, J. M. (1993). What Is Coefficient Alpha? An examination of theory and applications. Journal of Applied Psychology, 78(1), 98-104.

DeFusco, R. P., \& Unangst, E. T. (2013). Airport wildlife population management: A synthesis of airport practice (ACRP Synthesis 39). Retrieved from the Transportation Research Board on the National Academies website: http://www.trb.org/main/blurbs/169414.aspx 
DeFusco, R. P., Unangst, E. T. J., Cooley, T. R., \& Landry, J. M. (2015). Applying an SMS approach to wildlife hazard management (ACRP Report No. 145. Retrieved from the Transportation Research Board on the National Academies website: http://onlinepubs.trb. org/onlinepubs/acrp/acrp_rpt_145.pdf

DeVault, T. L., Blackwell, B. F., \& Belant, J. L. (Ed.) (2013). Wildlife in airport environments. Baltimore, MD: The Johns Hopkins University.

DeVon, H. A., Block, M. E., Wright, P. M., Ernst, D. M., Hayden, S. J., Lazzara, D. J., ...Polston, E. K. (2007). A psychometric toolbox for testing validity and reliability. Journal of Nursing Scholarship, 39(2), 155-164.

Dolbeer, R. A. (2006). Height distributions of birds as recorded by collisions with civil aircraft. Journal of Wildlife Management, 70(5), 1345-1350.

Dolbeer, R. A. (2009). Birds and aircraft: Fighting for airspace in ever more crowded skies. Journal of Human-Wildlife Conflicts, 3(2), 155-166.

Dolbeer, R. A. (2011). Increasing trend of damaging bird strikes with aircraft outside the airport boundary: implications for mitigation measures. Journal of Human-Wildlife Conflicts, 5(2), 235-248.

Dolbeer, R. A. (2018). Wildlife strikes to civil aircraft in the United States: 19902016 (Serial Report Number 23). Retrieved from the Federal Aviation Administration website: https://www.faa.gov/airports/airport_safety/wildlife/media/Wildlife-StrikeReport-1990-2016.pdf

Dolbeer, R. A., \& Barnes, W. J. (2017). Positive bias in bird strikes to engines on left side of aircraft. Human-Wildlife Conflicts, 11(1), 33-40.

Dolbeer, R. A., Weller, J. R., Anderson, A. M., \& Begier, M. J. (2016). Wildlife strikes to civil aircraft in the United States: 1990-2015 (Serial Report Number 22). Retrieved from the Federal Aviation Administration website: https://www.faa.gov/airports/airport_ safety/wildlife/media/Wildlife-StrikeReport-1990-2015.pdf

Doppler, M. S., Blackwell, B. F., DeVault, T. L., Juricic, E. F. (2015). Cowbird responses to aircraft with light tuned to their eyes: Implications for birdaircraft collisions. The Condor Ornithological Applications, 117(2), 165177. Retrieved from http://www.bioone.org/doi/full/10.1650/CONDOR-14157.1

Dwivedi, A., Mallawaarachchi, I., \& Alvarado, L. (2017). Analysis of small sample size studies using nonparametric bootstrap test with pooled resampling method. Statistics in Medicine, 36(14), 2187-2205. 
Electronic Code of Federal Regulations, Title 14, Chapter I, Subchapter D, Part 61. (2018). Available online at https://www.ecfr.gov/cgi-bin/textidx?SID=dba8ce6ce145b0affd50861a1bb4c5a2\&mc=true \&node=pt14.2.61 $\&$ rgn $=$ div 5

Electronic Code of Federal Regulations, Title 14, Chapter I, Subchapter H, Part 141. (2018). Available online at http://www.ecfr.gov/cgi-bin/textidx?tpl=/ecfrbrowse/Title14/14cfr141_main_02.tpl

Ertmer, P. A., \& Newby, T. J. (2013). Behaviorism, cognitivism, constructivism: Comparing critical features from an instructional design perspective. Performance Improvement Quarterly, 26(2), 43-71.

Eschenfelder, P., \& DeFusco, R. (2010, August). Bird strike mitigation beyond the airport. AeroSafety World, 5(7). Retrieved from http://flightsafety.org/aerosafety-world-magazine/august-2010/bird-strikemitigation-beyond-the-airport

Federal Aviation Administration (FAA). (2013). Reporting wildlife aircraft strikes (Advisory Circular 150/5200-32B). Retrieved from https://www.faa.gov/documentLibrary/media/ Advisory_Circular/AC_150_5200-32B.pdf

Federal Aviation Administration (FAA). (2016a). Pilot's handbook of aeronautical knowledge (FAA-H-8083-25B). Retrieved from https://www.faa.gov/regulations_policies/ handbooks_ manuals/aviation/phak/

Federal Aviation Administration (FAA). (2016b). Risk management handbook (FAA-H-8083-2). Retrieved from https://www.faa.gov/regulations_policies/handbooks_manuals/aviation/ media/FAA-H-8083-2.pdf

Federal Aviation Administration (FAA). (2016c). Air traffic organization policy: Air traffic control (JO 7110.65W CHG). Retrieved from https://www.faa.gov/documentlibrary/ media/order/atc.pdf

Federal Aviation Administration (FAA). (2017). Aeronautical information manual: Official guide to basic flight information and ATC procedures. Retrieved from https://www.faa.gov/air_traffic/publications/media/AIM_Basic_dtd_10-1217.pdf

Federal Aviation Administration (FAA). (2018). Administrator's fact book. Retrieved from https://www.faa.gov/news/media/2018_administrators_fact_book.pdf 
Field, A. (2009). Discovering statistics using SPSS. London: SAGE.

General Aviation Manufacturers Association (2018). 2017 annual report. Retrieved from https://gama.aero/wpcontent/uploads/GAMA_2017_AnnualReport_ForWeb_0518.pdf

International Civil Aviation Organization (ICAO). (2013). Annex 19 to the Convention on International Civil Aviation, Safety Management (1st ed.). Montreal, Canada: Author.

Junior, M. A., Shirazi, H., Cardoso, S., Brown, J., Speir, R., Seleznev, O., . . . McCall, E. (2009). Safety management systems for airports (ACRP Report $\mathrm{N}^{\mathrm{o}}$ 01, volume 2). Retrieved from the Transportation Research Board on the National Academies website: http://onlinepubs. trb.org/onlinepubs/acrp/acrp_rpt_001b.pdf

Keller, J. (2015). Unexpected transition from VFR to IMC: An examination of training protocols to mitigate pilot gaps in knowledge and performance (Unpublished doctoral dissertation). Purdue University, West Lafayette, IN.

Knecht, W., Ball, J., \& Lenz, M. (2010). Effects of video weather training products, web-based preflight weather briefing, and local versus non-local pilots on general aviation pilot weather knowledge and flight behavior, phase I (DOT/FAA/AM-10/1). Retrieved from http://www.faa.gov/data_research/research/med_humanfacs/oamtechreport s/2 010s/media/201001.pdf

Kochan, J. A., Jensen, R. S., Chubb, G. P., \& Hunter, D. R. (1997). A new approach to aeronautical decision-making: The expertise method. Retrieved from http://handle.dtic.mil/100.2/ADA323793

Laerd Statistics. (2018). Wilcoxon signed-rank test: Background and requirements. Retrieved from https://statistics.laerd.com/premium/spss/wsrt/wilcoxon-signed-rank-testin-spss-3.php

Ludwig, D. A., Andrews, C. R., Veen, N. R. J \& Laqui, C. (2007). Safety management systems for airports (ACRP Report No. 01, volume 1). Retrieved from the Transportation Research Board on the National Academies website: http://www.trb.org/main/blurbs/1590 30.aspx

Lynn, M.R. (1986). Determination and quantification of content validity. Nursing Research, 35(6), 382-385.

MacKinnon, B. (2004). Sharing the skies manual - An aviation industry guide to the management of wildlife hazards. Retrieved from the Government of 
Canada, Transport Canada website:

http://www.tc.gc.ca/eng/civilaviation/publications/tp13549-menu-2163.htm

Manuele, F. A. (2013). On the practice of safety. Hoboken, NJ: John Wiley \& Sons, Inc.

Marra, P. P., Dove, C. J., Dolbeer, R. A., Dahlan, N. F., Heacker, M., Whaton, J. F., Diggs, N. E., ... Henkes, G. A. (2009). Migratory Canada geese cause crash of US Airways flight 1549. Frontiers in Ecology and the Environment, 7(6), 297-301.

Mendonca, F. A. C. (2016). Exploiting science: Enhancing pilots'safety training to reduce the risk of bird strikes. Paper presented at the 2016 Bird Strike Committee USA Meeting, Chicago, IL. Presentation retrieved from https://www.aaae.org/aaae/AAAEDocs/ Meetings/2016/08/160807/Pres/26_Mendonca.pdf

Mendonca, F. A. C., \& Carney, T. Q. (2018, March). General aviation pilots' strategies to mitigate bird strikes. Paper presented at 104th Purdue Road School Transportation Conference and Expo, West Lafayette, IN. Abstract retrieved from https://roadschool. purdue.edu/roadschoolprogram/program.html

National Transportation Safety Board (NTSB). (1992). Britt Airways, Inc., Continental express flight 2574 in-flight structural breakup Embraer 120RT N33701 (NTSB/AAR-92/04). Retrieved from https://www.ntsb.gov/ investigations/AccidentReports/ Reports/ AAR9204.pdf

National Transportation Safety Board (NTSB). (2003). Aircraft accident brief (DCA01MA034). Retrieved from https://www.ntsb.gov/investigations/AccidentReports/ Reports/ AAB0203.pdf

National Transportation Safety Board (NTSB). (2009). Crash of Cessna 500, N113SH following an in-flight collision with large birds - Oklahoma City, Oklahoma (NTSB/AAR-09/05-PB2009-910405). Retrieved from https:/www.ntsb.gov/investigations/AccidentReports/ Reports/AAR0905.pdf

National Transportation Safety Board (NTSB). (2010). Loss of control on approach Colgan Air, Inc. operating as Continental connection flight 3407 Bombardier DHC-8-400, N200WQ (NTSB/AAR-10/01). Retrieved from https://www.ntsb.gov/investigations/ AccidentReports/Reports/AAR1001.pdf 
National Transportation Safety Board (NTSB). (2013a). Crash during a nighttime nonprecision instrument approach to landing UPS flight 1354 Airbus A300-600, N155UP (NTSB/AAR-14/02). Retrieved from https://www.ntsb.gov/investigations/ AccidentReports/Reports/AAR1402.pdf

National Transportation Safety Board (NTSB). (2013b). Descent below visual glidepath and impact with seawall Asiana Airlines flight 214, Boeing 777200ER, HL7742 - San Francisco, California (NTSB/AAR-14/01 PB2014105984). Retrieved from https://www.ntsb.gov/investigations/AccidentReports/Reports/AAR1401.p df

National Transportation Safety Board (NTSB). (2014). Crash following encounter with instrument meteorological conditions after departure from remote landing site (NTSB/AAR-14/03PB2014-108877). Retrieved from https://www.ntsb.gov/investigations/AccidentReports/Reports/AAR1403.p df

National Transportation Safety Board (NTSB). (2015). In-flight breakup during test flight Scaled Composites Spaceship Two, N339SS (NTSB/AAR15/02PB2015-105454). Retrieved from https://www.ntsb.gov/investigations/AccidentReports/Reports/AAR1502.p df

National Transportation Safety Board (NTSB). (2018a). National Transportation Safety Board aviation accident final report (GAA18CA071). Retrieved from

https://app.ntsb.gov/pdfgenerator/ReportGeneratorFile.ashx?EventID=2017 $1205 X 42203 \&$ AKey $=1 \&$ RType $=$ Final $\&$ IType $=$ CA

National Transportation Safety Board (NTSB). (2018b). National Transportation Safety Board aviation accident factual report (WPR18CA100). Retrieved from

https://app.ntsb.gov/pdfgenerator/ReportGeneratorFile.ashx ?EventID=2018 0228X03202\&AKey $=1 \&$ RType $=$ Final $\&$ IType $=$ CA

Nicholson, R., \& Reed, W. S. (2011, July). Strategies for prevention of bird-strike events. BOEING Aero Magazine, 3(11). Retrieved from http://www.boeing.com/commercial/ aeromagazine/articles/2011_q3/4/

Nohara, T. (2016). Illustrating the use of avian radar for off-airport bird hazard alerting. Paper presented at the 2016 Bird Strike Committee USA Meeting, Chicago, IL. Presentation retrieved from 
http://www.aaae.org/aaae/AAAEDocs/Meetings/2016/

08/160807/Pres/05_Nohara.pdf

O’Callaghan, J. (n.d.). Bird-strike certification standards and damage mitigation. Retrieved from the National Transportation Safety Board website: https://www.ntsb.gov/news/events/documents/oklahoma_city_ok2_web_bird_strike_cert_and_damage_john_ocallaghan.pdf

O’Hare, D., Mullen, N., \& Arnold, A. (2010). Enhancing aeronautical decision making through case-based reflection. The International Journal of Aviation Psychology, 20(1), 173-178.

Patton, M. Q. (2015). Qualitative research \& evaluation methods. London, United Kingdom: SAGE.

Polit, D. F. \& Beck, C. T. (2006). The Content Validity Index: Are you sure you know what's being reported? Critique and recommendations. Research in Nursing \& Health, 29(5), 489-497.

Polit, D. F., Beck, C. T., \& Owen, S. V. (2007). Is the CVI an acceptable indicator of content validity? Appraisal and recommendations. Research in Nursing \& Health, 30(4), 459-467.

Privitera, G. J. (2015). Statistics for the behavioral sciences. Thousand Oaks, CA: SAGE.

Reason, J. (1997). Managing the risks of organizational accidents. Aldershot, England: Ashgate.

Reason, J. (1998). Achieving a safe culture: Theory and practice. Journal of Work and Stress, 12(3), 293-306, doi:10.1080/02678379808256868

Rillstone, D. J., \& Dineen, C. M. (2013). Airport responsibility for wildlife management (ACRP Legal Research Digest No. 20). Retrieved from the Transportation Research Board on the National Academies website: http://www.trb.org/main/ blurbs/169414.aspx

Sekaran, U., \& Bougie, R. (2013). Research methods for business. London, United Kingdom: SAGE.

Thaden, T. L. V., \& Gibbons, A. M. (2008). The safety culture indicator scale measurement system (SCISMS). (DOT/FAA/AR-xx/xx). Retrieved from the Federal Aviation Administration website: http://www.tc.faa.gov/logistics/grants/pdf/2001/01-G-015.pdf

Wang, M., \& Riffek, M. (2011). Making the right conclusions based on wrong results and small sample sizes: Interpretation of statistical tests in ecotoxicology. Ecotoxicology \& Environmental Safety, 74(4), 684-693. 
Wiegmann, D. A., von Thaden, T. L. V., \& Gibbons, A. M. (2007). A review of safety culture theory and its potential application to traffic safety. Retrieved from the Transportation Research Board on the National Academies website: http://trid.trb.org/view.aspx?id=809716

Winter, S. R., Fanjoy, R. O., Lu, C. T., Carney, T. Q., \& Greenan, J. P. (2014). Decision to use an airframe parachute in a flight training environment. Journal of Aviation Technology and Engineering, 3(2), 28-34. 